\title{
A serine/threonine kinase, Cot/Tpl2, modulates bacterial DNA-induced IL-12 production and Th cell differentiation
}

\author{
Kenji Sugimoto, ${ }^{1,2}$ Mutsuhiro Ohata, ${ }^{1}$ Jun Miyoshi, ${ }^{3}$ Hiroyoshi Ishizaki, ${ }^{3,4}$ Naotake Tsuboi, ${ }^{1,5}$ \\ Akio Masuda, ${ }^{1}$ Yasunobu Yoshikai, ${ }^{6}$ Masaya Takamoto, ${ }^{7}$ Kazuo Sugane, ${ }^{7}$ Seiichi Matsuo, ${ }^{5}$ \\ Yasuhiro Shimada, ${ }^{2}$ and Tetsuya Matsuguchi ${ }^{8}$
}

\begin{abstract}
1Division of Host Defense, Center for Neural Disease and Cancer, and 'Department of Anesthesiology, Nagoya University Graduate School of Medicine, Nagoya, Japan. ${ }^{3}$ Department of Molecular Biology, Osaka Medical Center for Cancer and Cardiovascular Diseases, Osaka, Japan.

${ }^{4}$ KAN Research Institute, Kyoto, Japan. ${ }^{5}$ Division of Clinical Immunology, Department of Medicine, Nagoya University Graduate School of Medicine, Nagoya, Japan. ${ }^{6}$ Division of Host Defense, Research Center for Prevention of Infectious Diseases, Medical Institute of Bioregulation, Kyushu University, Fukuoka, Japan. 'Department of Immunology and Infectious Diseases, Shinshu University Graduate School of Medicine, Nagano, Japan. ${ }^{8}$ Division of Biochemistry and Molecular Dentistry, Department of Developmental Medicine, Kagoshima University Graduate School of Medical and Dental Sciences, Kagoshima, Japan.
\end{abstract}

\begin{abstract}
A serine/threonine protein kinase, Cot/Tpl2, is indispensable for extracellular signal-regulated kinase (ERK) activation and production of TNF- $\alpha$ and PGE 2 in LPS-stimulated macrophages. We show here that Cot/Tpl2 is also activated by other Toll-like receptor (TLR) ligands. Bacterial DNA rich in the dinucleotide CG (CpG-DNA), unlike LPS or synthetic lipopeptide, activated ERK in a Cot/Tpl2-independent manner. Peritoneal macrophages and bone marrow-derived DCs from Cot/ $\mathrm{T} \mathrm{pl}^{-/-}$mice produced significantly more IL-12 in response to CpGDNA than those from WT mice. Enhanced IL-12 production in Cot/Tpl2 ${ }^{-/}$macrophages is, at least partly, regulated at the transcriptional level, and the elevated IL-12 mRNA level in Cot/Tpl2 ${ }^{-/}$macrophages is accompanied by decreased amounts of IL-12 repressors, such as c-musculoaponeurotic fibrosarcoma (c-Maf) and GATA sequence in the IL-12 promoter-binding protein (GA-12-binding protein; GAP-12) in the nucleus. Consistently, Cot/T $\mathrm{pl}^{-/-}$mice showed Th1-skewed antigen-specific immune responses upon OVA immunization and Leishmania major infection in vivo. These results indicate that $\mathrm{Cot} / \mathrm{T} \mathrm{pl} 2$ is an important negative regulator of Th1-type adaptive immunity, that it achieves this regulation by inhibiting IL-12 production from accessory cells, and that it might be a potential target molecule in CPG-DNA-guided vaccination.
\end{abstract}

\section{Introduction}

Macrophages play a central role in the innate immune response to a wide range of bacterial components such as LPS, lipoprotein, peptidoglycan, flagellin, and bacterial DNA rich in the dinucleotide CG (CpG-DNA). On activation by these components, macrophages produce cytokines, such as TNF- $\alpha$, IL-12, and IL-10, and secondary mediators, such as PGs and $\mathrm{NO}(1,2)$. DCs also sense the types of pathogens and deliver critical information to antigen-reactive $\mathrm{T}$ cells. Upon activation by pathogens, DCs express high levels of MHC class II and costimulator molecules, such as CD80 and CD86, on their cell surface and become a major source of IL-12, which greatly potentiates IFN- $\gamma$-producing Th1-type $T$ cell differentiation $(3,4)$. Thus, the maturation and cytokine production profiles of DCs are critical for the linkage between innate and adaptive immunity.

Understanding how bacterial components activate macrophages and DCs was greatly expedited by the identification of the Toll-

Nonstandard abbreviations used: c-Maf, c-musculoaponeurotic fibrosarcoma; CPG-DNA, bacterial DNA rich in the dinucleotide CG; EMSA, electrophoretic mobility shift assay; ERK, extracellular signal-regulated kinase; GA-12, GATA sequence in the IL-12 promoter; GAP-12, GA-12-binding protein; HEK, human embryonic kidney; IFA, incomplete Freund's adjuvant; MD2, myeloid differentiation-2; MEK1, MAPK/ERK kinase-1; PAMP, pathogen-associated molecular pattern; RPA, RNA protection assay; TLR, Toll-like receptor.

Conflict of interest: The authors have declared that no conflict of interest exists.

Citation for this article: J. Clin. Invest. 114:857-866 (2004)

doi:10.1172/JCI200420014 like receptors (TLRs). The phenotypes of animals with functionally defective TLRs (both naturally occurring and artificially manipulated) suggest that each TLR is essential for the recognition of specific pathogen-associated molecular patterns (PAMPs) (5). Although TLRs share some downstream signaling molecules, various reports have also suggested difference among the biological responses induced by TLRs (5).

A serine/threonine protein kinase, Cot, also known as Tpl2, was originally identified as an oncogene by the SHOK cell transfection assay $(6,7)$ and also identified as a target for proviral integration in MoMuLV-induced rat T cell lymphomas and MMTV-induced mammary carcinomas $(8,9)$. Cot/Tpl2 belongs to the mitogenactivated protein kinase kinase kinase family and can activate both the extracellular signal-regulated kinase (ERK) and the JNK signaling pathways $(10,11)$. Cot/Tpl2 has also been implicated in

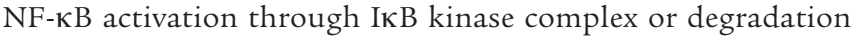
of the inhibitory p105 protein (12-14), which has recently been reported to stabilize and inhibit Cot/Tpl $2(15,16)$. Recently, Tsichlis and colleagues reported that the Cot/Tpl2 kinase plays an important role in LPS signaling $(17,18)$. According to their reports, Cot/Tpl2-/- macrophages are defective in ERK activation induced by LPS, while the activation of other MAPKs remains intact. The lack of ERK activation in Cot/Tpl2-/- macrophages results in impaired secretion of TNF- $\alpha$ and $\mathrm{PGE}_{2}-$ key regulators of both inflammation and immunity - in response to LPS $(17,18)$. A quite recent paper also indicated an essential role of Cot/Tpl2 in the 
A

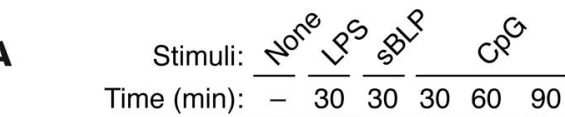

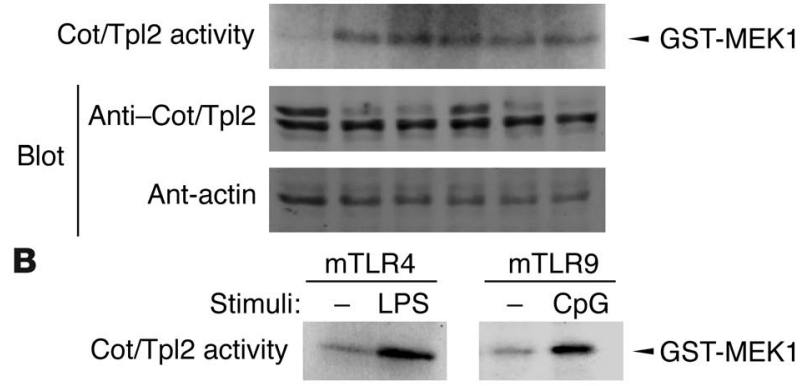

\section{Figure 1}

Cot/Tpl2 activation by TLR ligands. (A) RAW 264.7 cells were stimulated with $1 \mu \mathrm{g} / \mathrm{ml}$ LPS, $1 \mu \mathrm{g} / \mathrm{ml}$ synthetic lipopeptide, or $1 \mu \mathrm{M}$ CpG-DNA for the indicated periods. In vitro kinase assays were performed with an Ab against Cot/Tpl2 and GST-MEK1 as the substrate. As a control, Western blot analyses were performed with Ab's against Cot/Tpl2 and $\beta$-actin. sBLP, synthetic bacterial lipopeptide. (B) HEK 293 cells were transiently transfected with Flag-tagged Cot/Tpl2 in combination with either mouse TLR4 plus CD14 plus MD2 (mTLR4) or mouse TLR9 (mTLR9). Transfectants were stimulated for 30 minutes with $1 \mu \mathrm{g} / \mathrm{ml}$ LPS or $1 \mu \mathrm{M}$ CpG-DNA, respectively. In vitro kinase assay was performed with anti-Flag Ab on GST-MEK1 as the substrate.

downstream signals of CD40 and TNF- $\alpha$ receptor in B cells (19). However, it is largely unknown whether Cot/Tpl2 is also involved in macrophage responses to bacterial components other than LPS or in signal transduction of other types of immune cells.

In this study, using a separate line of $\operatorname{Cot} / \mathrm{Tpl} 2^{-/-}$mice, we demonstrate that Cot/Tpl2-/- macrophages undergo normal ERK activation and produce significantly more IL-12 in response to CpGDNA than their normal counterparts. Similarly, Cot/Tpl2-/- DCs produced higher levels of IL-12 in response to LPS and CPG-DNA than WT DCs. Consistently, after OVA immunization and Leishmania major infection in vivo, Cot/ $\mathrm{Tpl} 2^{-/-}$mice showed antigenspecific immune responses polarized toward Th1 type.

\section{Results}

LPS, synthetic lipopeptide, and CPG-DNA induce Cot/Tpl2 activation in macrophages. To address the involvement of Cot/Tpl2 in various TLR signals, we measured the Cot/Tpl2 kinase activity using GST-MAPK/ERK kinase-1 (GST-MEK1) as the substrate in RAW 264.7 cells stimulated with LPS, synthetic lipopeptide, or CpGDNA. All 3 TLR ligands rapidly activated Cot/Tpl2 (Figure 1A). To rule out the possible contamination of LPS in the CPG-DNA reagent we used, human embryonic kidney (HEK) 293 cells transiently transfected either with mouse TLR9 or with mouse TLR4 combined with myeloid differentiation-2 (MD2) and CD14 were analyzed. The transfectants were solely responsive to CpG-DNA or LPS, respectively, as determined by NF-KB activation assays (data not shown). When the expression plasmid for Flag-tagged Cot/ $\mathrm{Tpl} 2$ was cotransfected in this cell system, in vitro kinase assays with Flag immunoprecipitates revealed that CpG-DNA induces Cot/Tpl2 activation in HEK 293 cells transfected with mouse TLR9 but not in those transfected with mouse TLR4 plus MD2 and CD14. Thus CPG-DNA, but not the contaminating LPS, is capable of Cot/Tpl2 activation through mouse TLR9 (Figure 1B).

Generation of Cot/Tpl2-/ mice. To address the physiological role of $\mathrm{Cot} / \mathrm{Tpl} 2$ in TLR signaling, mice deficient for $\mathrm{Cot} / \mathrm{Tpl} 2$ were generated by replacement of the $3^{\prime}$ half of coding exon 2 and the $5^{\prime}$ half of exon 3, encoding the ATP-binding domain (residues 123-224 of the total 467 amino acids of Cot/Tpl2 protein), with a neo-resistance gene cassette (Figure 2A). Mice heterozygous and homozygous for $\mathrm{Cot} / \mathrm{Tp} 2$ deletion were assessed by Southern blot analysis for a correct targeting event (Figure 2B). After heterozygous mating, Cot/ $\mathrm{Tpl} 2^{-/-}$mice were born at the expected mendelian frequency, with life expectancy no different from that of WT littermates. RT-PCR (Figure 2C) and Western blot analysis (Figure 2D) confirmed that Cot/Tpl2 mRNA and protein were absent in the generated $\mathrm{Cot} / \mathrm{Tpl} 2^{-/-}$mice.

\section{Figure 2}

Targeted disruption of the Cot/Tpl2 gene. (A) The schematic structure of the mouse Cot/Tpl2 gene with exon 1 (ex1) to exon 7 is shown at the top. A targeting vector was designed to remove a part of exons 2 and 3 , encoding the ATP-binding domain of $\mathrm{Cot} / \mathrm{Tpl}$ 2. Homologous recombination was verified using informative restriction fragments and diagnostic probes as indicated. (B) Southern hybridization using EcoRI-digested DNA extracted from mouse tails identified the expected genotypes (7.5-kb WT and 4.2-kb mutant fragments). (C) RT-PCR analysis by Cot/Tpl2-specific primers in the targeted region (290 bp) identified the expected genotypes. (D) Western blot analysis of proteins extracted from the heart using anti-Cot/Tpl2 Ab for the nontargeted region identified each genotype (the 58-kDa and $52-\mathrm{kDa}$ forms of the Cot/Tpl2 protein).
A

$\mathrm{Cot} / \mathrm{Tpl}$ gene

Targeting vector

Targeted allele
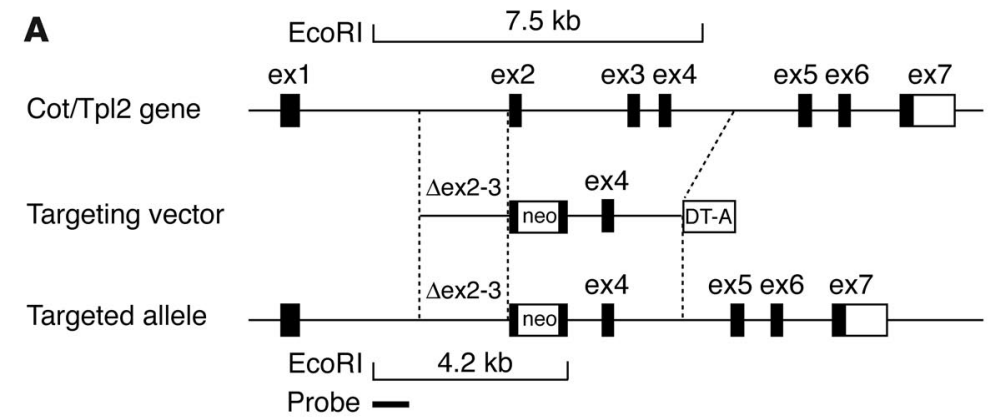

B

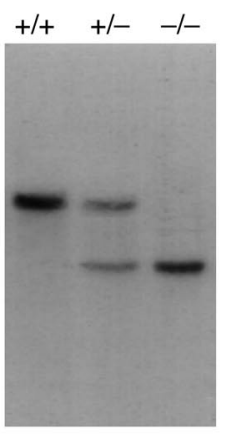

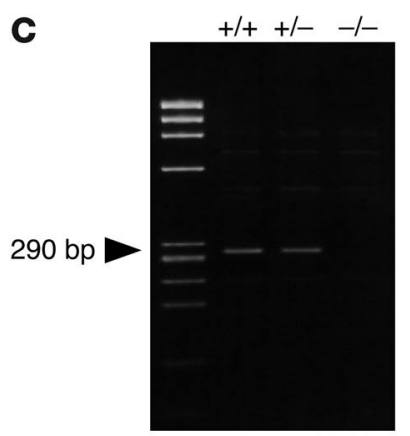

D

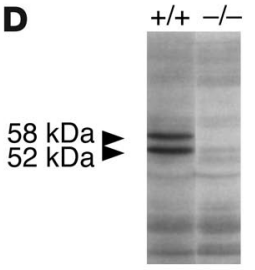


A

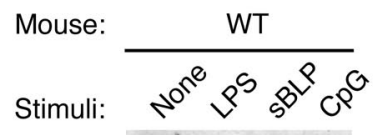

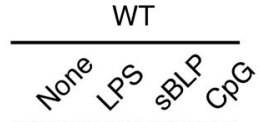

Phospho-ERK

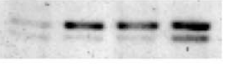

ERK

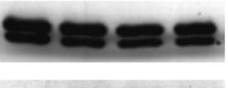

Phospho-p38 MAPK

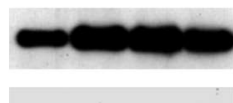

p38 MAPK

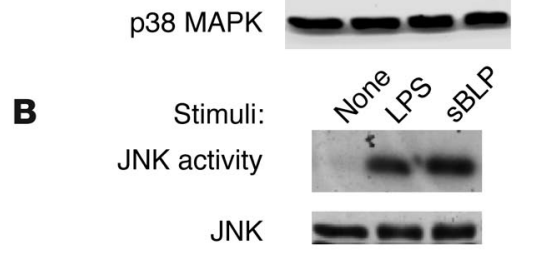

J
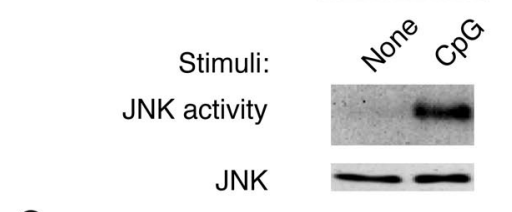

C $\mathrm{CPG}(1 \mu \mathrm{M})$
$\mathrm{U} 0126(\mu \mathrm{M})$ $-++++$ Phospho-ERK

ERK

$\begin{array}{ccccc}0 & 0 & 1 & 2.5 & 5 \\ \vdots & =\end{array}$

Sta
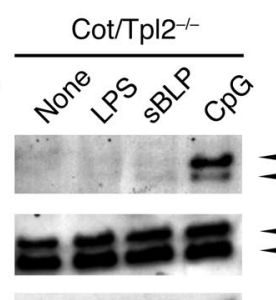

- Phospho-p44 ERK Phospho-p42 ERK

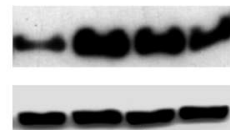

$=$ p44 ERK
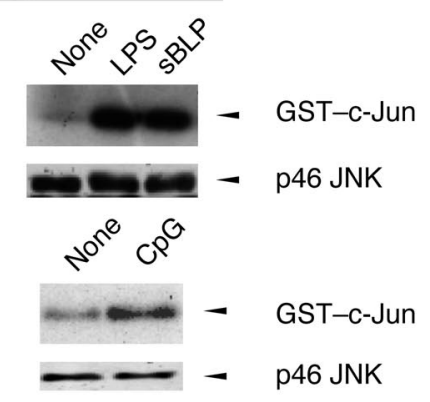

GST-C-Jun

$\mathrm{CpG}(1 \mu \mathrm{M})-+++$

Staurosporine $(\mu \mathrm{M}) \quad 0 \quad 0 \quad 0.25 \quad 1 \quad 2.5$

Phospho-ERK

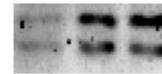

ERK

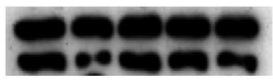

\section{Figure 3}

Cot/Tpl2 is not required for CpG-DNA-induced ERK phosphorylation. (A) WT and Cot $/ \mathrm{Tpl}^{-1-}$ macrophages were unstimulated or stimulated with $1 \mu \mathrm{g} / \mathrm{ml} \mathrm{LPS}, 1 \mu \mathrm{g} / \mathrm{ml}$ synthetic lipopeptide, or $1 \mu \mathrm{M}$ CpG-DNA for 30 minutes. Western blot analyses were performed with Ab's against phospho-ERK1/2, ERK1/2, phospho-p38 MAPK, or p38 MAPK. (B) In vitro kinase assay of anti-JNK1 immunoprecipitates was performed on GST-C-Jun as the substrate. As a control, Western blot analysis was performed with anti-JNK1 Ab. (C) Cot/Tpl2-/- macrophages were pretreated with U0126 or staurosporine for 30 minutes, and then left unstimulated or stimulated with $1 \mu \mathrm{M}$ CpG-DNA. Western blot analyses were performed with the Ab against phospho-ERK1/2 or ERK1/2.

CpG-DNA, but not LPS or synthetic lipopeptide, induces ERK activation in $\mathrm{Cot} / \mathrm{Tpl} 2^{-/-}$macrophages. Using peritoneal macrophages from the Cot/Tpl2--- mice, we examined the phosphorylation of ERK1/2 before and after stimulation with synthetic lipopeptide, CpG-DNA, or LPS using a mAb specific to the phosphorylated forms of ERKs. As previously reported $(17,18)$, Cot/Tpl2-/macrophages showed defective ERK phosphorylation in response to LPS (Figure 3A). They were also defective in ERK phosphorylation in response to synthetic lipopeptide. In contrast, Cot/Tpl2-/- macrophages showed normal ERK phosphorylation in response to CPG-DNA. JNK1, JNK2, and p38 MAPK were normally activated in response to all 3 TLR ligands (Figure $3, \mathrm{~A}$ and $\mathrm{B}$ ).

As ERK appeared to be activated by CPG-DNA independently of Cot/Tpl2, we sought to analyze the molecular mechanisms of CpG-DNA-induced ERK activation in Cot $/ \mathrm{Tp} 12^{-/-}$macrophages. We first tested the effects of a specific MEK1/2 inhibitor, U0126. ERK phosphorylation induced by CpG-DNA in Cot/Tpl2-macrophages was sensitive to pretreatment by U0126 (Figure 3C), which indicates that this signaling is MEK1/2dependent. We obtained similar results from PD98059, another MEK1/2-specific inhibitor (data not shown). To explore the upstream activation mechanisms of the MEK/ERK pathway, we next utilized a PKC inhibitor, staurosporine. Pretreatment with staurosporine abrogated the ERK phosphorylation induced by CPG-DNA in $\mathrm{Cot} / \mathrm{Tpl} 2^{-/-}$macrophages, indicating that a protein kinase(s) sensitive to staurosporine, but not $\mathrm{Cot} / \mathrm{Tpl} 2$, is critically involved in the MEK/ERK activation by CPG-DNA (Figure 3C).

Cytokine secretion profile of Cot/Tpl2-/macrophages in response to LPS and CPG-DNA. To compare the regulatory roles of Cot/Tpl2 in cytokine production induced by LPS and CPGDNA, both WT and Cot/Tpl2-/- macrophages were stimulated with LPS and CPG-DNA for 24 hours. As previously reported (17), the Cot/Tpl2-/- macrophages showed impaired TNF- $\alpha$ production compared with the WT macrophages in response to LPS. Although CPG-DNA induced a relatively small amount of TNF- $\alpha$ production, the induced TNF- $\alpha$ level was slightly lower in $\mathrm{Cot} / \mathrm{Tpl} 2^{-/-}$macrophages. In contrast, the CpG-DNA-treated Cot/Tpl2I- macrophages showed significantly increased IL-12 production compared with the WT counterparts. Additionally, IL-10 production induced by LPS or CPG-DNA was enhanced in the Cot/ $\mathrm{Tpl} 2^{--}$macrophages (Figure 4A). To analyze the role of ERK activation in CPG-DNA-induced IL-12 production from macrophages, we pretreated the cells with U0126. At $1 \mu \mathrm{M}$ of U0126, which was sufficient to inhibit ERK activation (Figure 3C), IL-12 production from both the WT and the Cot/Tpl2-/- macrophages was only moderately decreased (Figure 4B). Thus, ERK activation does not appear to be essential for CPG-DNA-induced IL-12 production in the presence or absence of $\mathrm{Cot} / \mathrm{Tpl}$.

Increased IL-12 mRNA in Cot/Tpl2-/- macrophages stimulated with $L P S$ and CPG-DNA. It has been reported that TNF- $\alpha$ production by macrophages in response to LPS stimulation is regulated at both transcriptional and posttranscriptional levels, whereas IL-12 production is regulated mainly at the transcriptional level (20). To assess the levels of TNF- $\alpha$ and IL-12 mRNA in response to LPS or CPG-DNA, peritoneal macrophages were treated with LPS or CPG-DNA, and total RNA was extracted and subjected to Northern blot analysis or RNA protection assay (RPA). Surprisingly, unlike in a previous report (17), LPS-induced TNF- $\alpha$ mRNA levels were consistently lower in the $\mathrm{Cot} / \mathrm{Tpl} 2^{-/-}$macrophages than in the WT macrophages (Figure 4C). CpG-DNA-induced TNF- $\alpha$ mRNA levels in the Cot/Tpl2 $/$ - macrophages were similar to those in the WT macrophages. Thus, the reduction of TNF- $\alpha$ secretion induced by LPS in the Cot/Tpl2/- macrophages seems at least partly regulated at the transcriptional level. In contrast, IL-12 p40 and p35 mRNA levels were significantly higher in the Cot/Tpl2-macrophages than in the WT macrophages in response to both LPS and CPG-DNA (Figure 4C). 

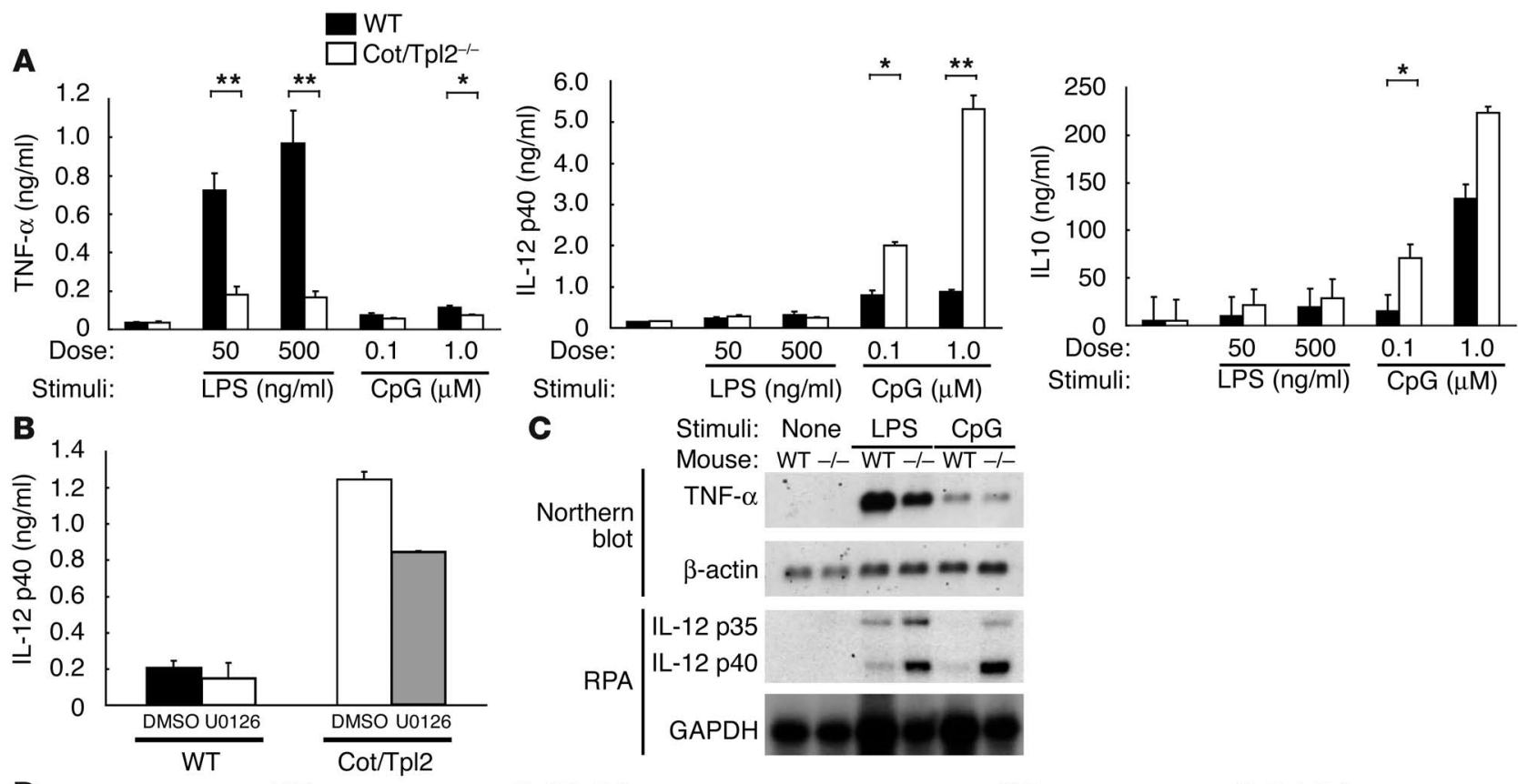

C

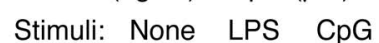

Stimuli:
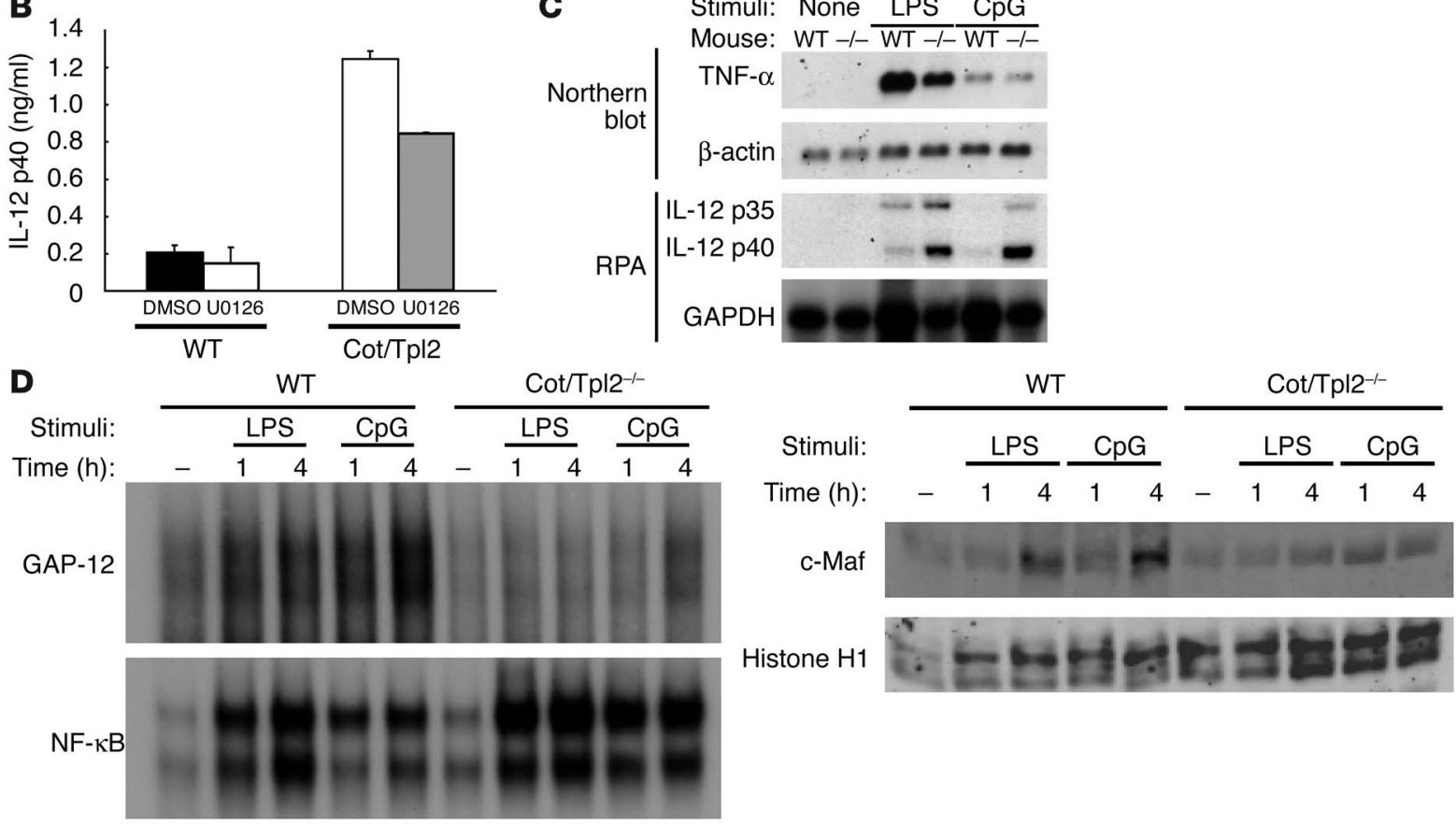

Histone $\mathrm{H} 1$

\section{Figure 4}

CpG-DNA-treated Cot/Tpl2-/- macrophages showed significantly increased IL-12 production. (A) WT (black bars) and Cot/Tpl2-/- (white bars) macrophages were stimulated with LPS or CpG-DNA for 24 hours. Levels of TNF- $\alpha$, IL-12 p40, and IL-10 in culture supernatants were measured by ELISA. ${ }^{*} P<0.05$ compared with WT. ${ }^{* *} P<0.01$ compared with WT. (B) WT and Cot/Tpl2-- macrophages were pretreated with $1 \mu \mathrm{M}$ U0126 and stimulated with $1 \mu \mathrm{M} \mathrm{CpG-DNA}$ for 8 hours. The level of IL-12 p40 in culture supernatants was measured by ELISA. Data are expressed as mean \pm SD and are representative of 3 independent experiments. (C) WT and Cot $/ T$ pl $2^{-/}$macrophages were treated for 2 hours with $1 \mu \mathrm{g} / \mathrm{ml}$ LPS or for 4 hours with $1 \mu \mathrm{M}$ CpG-DNA. Total RNA extracted from peritoneal macrophages was subjected to Northern blot analysis and RNA protection assay (RPA). (D) WT and Cot/Tpl2-- macrophages were unstimulated or stimulated with $1 \mu \mathrm{g} / \mathrm{ml}$ LPS or $1 \mu \mathrm{M}$ CpG-DNA for the indicated times. Nuclear extracts were subjected to EMSA to evaluate DNA-binding activities of NF-KB or GAP-12. The same nuclear extracts were subjected to Western blot analyses with Ab's against c-Maf and histone $\mathrm{H} 1$.

Changes of nuclear transcription factors in Cot/Tpl2-/- macrophages. Transcription of IL-12 p40 is regulated by the binding of positive transcription factors, such as NF- $\mathrm{KB}, \mathrm{C} / \mathrm{EBP} \beta$, and PU.1, to the 5' transcriptional regulatory region (21). Recently, 2 repressors have been reported for the IL-12 p40 gene expression, namely c-musculoaponeurotic fibrosarcoma (c-Maf) and GATA sequence in the IL-12 promoter-binding protein (GA-12-binding protein; GAP-12) (21, 22). We thus performed electrophoretic mobility shift assay (EMSA) to analyze DNA-binding activities of the 5 ' promoter of the IL-12 $\mathrm{p} 40$ gene in Cot/Tpl2 $/-$ macrophages. Stimulation of the Cot/ Tpl2 $/-$ macrophages with LPS or CpG-DNA induced DNA binding of NF- $\mathrm{KB}$ at a similar level to that in the WT macrophages (Figure 4D). We next performed EMSA using the GA-12 site of the mouse
IL-12 p40 gene, which is the binding site for the putative negative transcriptional regulator GAP-12 (21). In the WT macrophages, stimulation with either LPS or CPG-DNA induced protein binding to the GA-12 probe, whereas the protein-DNA complex was scarcely increased in the Cot/Tpl2 $/-$ macrophages (Figure $4 \mathrm{D})$. We then examined the nuclear content of c-Maf protein and found that c-Maf protein was increased after LPS and CPG-DNA treatment in the nuclei of WT macrophages. This c-Maf induction in the nucleus was severely impaired in the Cot/Tpl2-/- macrophages (Figure 4D). We also found that c-Maf mRNA levels after LPS or CPG-DNA stimulation were lower in the Cot/Tpl2/- macrophages (data not shown), which indicates that c-Maf expression was inhibited at the transcriptional level in the absence of Cot/Tpl2. 
A

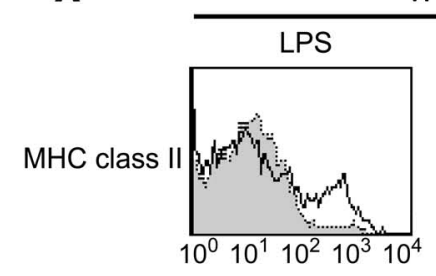

CD40

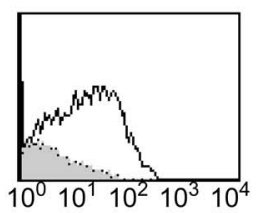

CD86

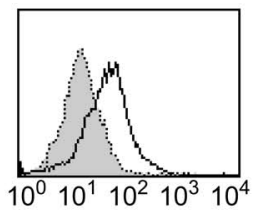

WT
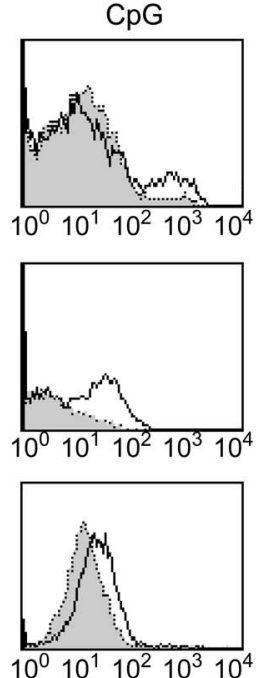

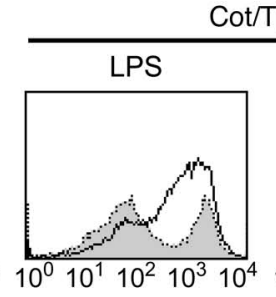

$\mathrm{Cot} / \mathrm{Tpl} 2^{-1-}$
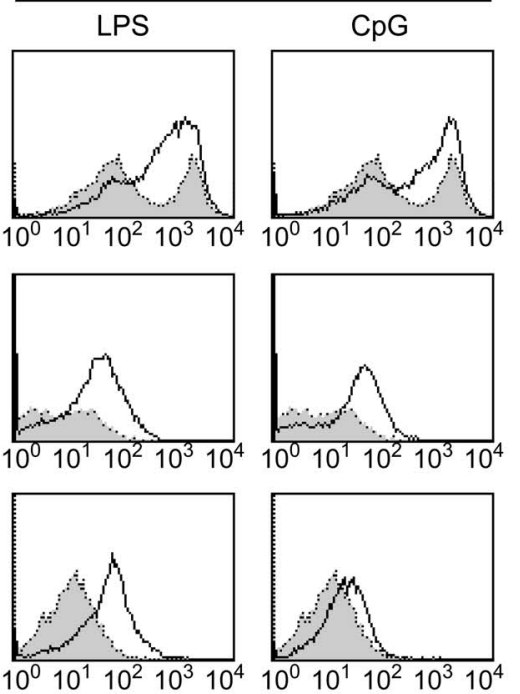

B

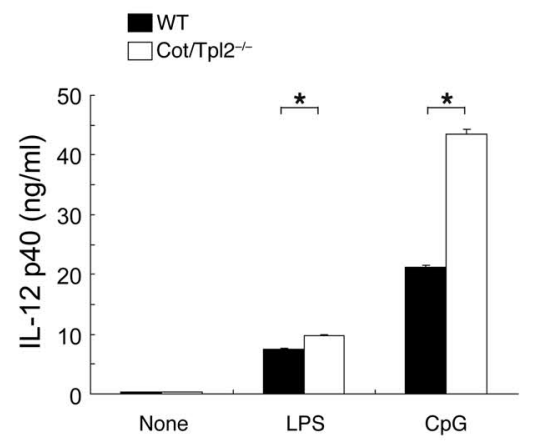

\section{Figure 5}

Maturation and cytokine production of DCs. (A) On day 5, bone marrow-derived DCs from WT or Cot/Tpl2 ${ }^{-/-}$mice were left unstimulated (shaded histograms) or stimulated with $1 \mu \mathrm{g} / \mathrm{ml}$ LPS or $1 \mu \mathrm{M}$ CpG-DNA (open histograms) for 24 hours. The DCs were subjected to MHC class II, CD40, and CD86 expression analyses by flow cytometry. (B) Immature WT (black bars) and Cot/Tpl2-/- (white bars) DCs (positively selected using magnetized $A b$ for $C D 11 c$ ) were unstimulated or stimulated with $1 \mu \mathrm{g} / \mathrm{ml}$ LPS or $1 \mu \mathrm{M}$ CpG-DNA for 24 hours. IL-12 p40 in culture supernatants was measured by ELISA. Data are expressed as mean of wells \pm SD and are representative of 3 independent experiments. ${ }^{*} P<0.05$.

Effect of Cot/Tpl2 deficiency on the maturation and IL-12 production of $D C s$. Like macrophages, DCs have been reported to express significant amounts of TLRs (5). In order to assess the roles of Cot/Tpl2 in TLR signals in DCs, we isolated immature DCs from the bone marrow of WT and Cot/Tpl2 $/-$ mice and examined their maturation and cytokine secretion in response to LPS and CPG-DNA. The Cot/Tpl2 ${ }^{--}$DCs treated with LPS and CpG-DNA did upregulate the surface expression of MHC class II, CD40, and CD86 (Figure $5 \mathrm{~A}$ ), indicating that $\mathrm{Cot} / \mathrm{Tpl} 2$ is not necessary in the maturation of DCs. Unlike CD40 and CD86 expression, the MHC class II surface expression on untreated Cot/T pl2-/- DCs was consistently higher than that on WT counterparts. The Cot/Tpl2-/- DCs produced significantly larger amounts of IL-12 in the presence of either LPS or CpG-DNA. Thus, as in macrophages, Cot/Tpl2 appears to play an inhibitory role in the IL-12 production in DCs (Figure 5B).

Increased Th1 response to OVA immunization in Cot/Tpl2-- mice. Since IL-12 production from DCs is decisive in determining the nature of the antigen-specific $\mathrm{T}$ cell response that follows, we next analyzed the immune responses of Cot/Tpl2 $2^{--}$mice in vivo after immunization with OVA. Cot/Tpl2 $2^{--}$and WT mice were immunized in the footpad with OVA mixed with CFA, and adaptive immune responses were analyzed 9 days after immunization. T cells derived from the draining lymph nodes of Cot/Tpl2 $/-$ mice showed enhanced proliferation in vitro in response to antigen stimulation compared with the WT T cells (Figure 6A), suggesting that the specific priming of $\mathrm{T}$ cells was enhanced in Cot/Tpl2-- mice. We purified CD4 ${ }^{+} \mathrm{T}$ cells from lymph nodes using magnetic beads conjugated with CD4 Ab. $\mathrm{CD}^{+} \mathrm{T}$ cells from OVA-sensitized Cot/T $\mathrm{pl} 2^{-/-}$mice produced a significantly higher amount of IFN- $\gamma$ and a lower amount of IL-4 on antigen stimulation than did those from control mice (Figure 6B).

Analysis of antigen-specific Ig responses in the sera showed that the Cot/Tpl2-/- mice consistently produced higher amounts of
OVA-specific IgG2a after immunization (Figure 6C). There was no difference of OVA-specific IgG1 and IgE concentrations between the 2 groups of mice. On immunization with OVA mixed with alum, a strong promoter of Th 2 responses, OVA-specific IgG1 and $\mathrm{IgE}$ responses were decreased in the $\mathrm{Cot} / \mathrm{Tpl} 2^{-/-}$mice compared with the WT mice (Figure 6D). Moreover, we obtained similar results when LPS or CPG-DNA was used as an adjuvant. In Cot/ $\mathrm{Tpl} 2^{-/-}$mice, IFN- $\gamma$ production is enhanced in $\mathrm{CD}^{+} \mathrm{T}$ cells sensitized with OVA mixed with CPG-DNA. In contrast, IL-4 production is decreased in $\mathrm{CD}^{+} \mathrm{T}$ cells sensitized with OVA mixed with LPS or CpG-DNA (Figure 6E).

Increased Th1 response to L. major infection in Cot/Tpl2-/- mice. Finally, we examined the immune response to L. major, an infection model in which adequate Th1 development is required for disease control. To test this, we infected WT and Cot/Tpl2-/- mice with $L$. major. We then monitored inflammatory responses to the infection by measuring footpad swelling for 12 weeks and measuring parasite loads in the popliteal lymph nodes after 6 weeks. $\mathrm{Cot} / \mathrm{T} \mathrm{pl}^{-/-}$mice developed lesions that were almost identical in size to those in WT mice (Figure 7A). Consistently, parasite load in $\mathrm{Cot} / \mathrm{Tpl} 2^{--}$mice was indistinguishable from that in WT mice (Figure $7 \mathrm{~B})$. $\mathrm{CD}^{+} \mathrm{T}$ cells from $L$. major-infected Cot/T $\mathrm{pl} 2^{-/-}$mice produced a significantly higher amount of IFN- $\gamma$ and a lower amount of IL-4 than did those from WT mice after stimulation with the soluble L. major antigen in vitro (Figure 7C).

\section{Discussion}

Properly stimulated TLRs activate various signal transduction pathways including NF-кB and MAPKs. Previous work had shown that Cot/Tpl2 is obligatory for the activation of ERK1/2 in LPS-stimulated macrophages $(17,18)$. We show here that all of the 3 TLR ligands examined, LPS, synthetic lipopeptide, and CpG-DNA, activate Cot/ 
A

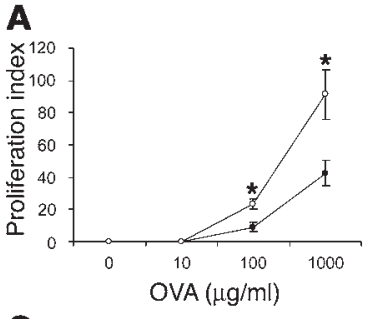

C
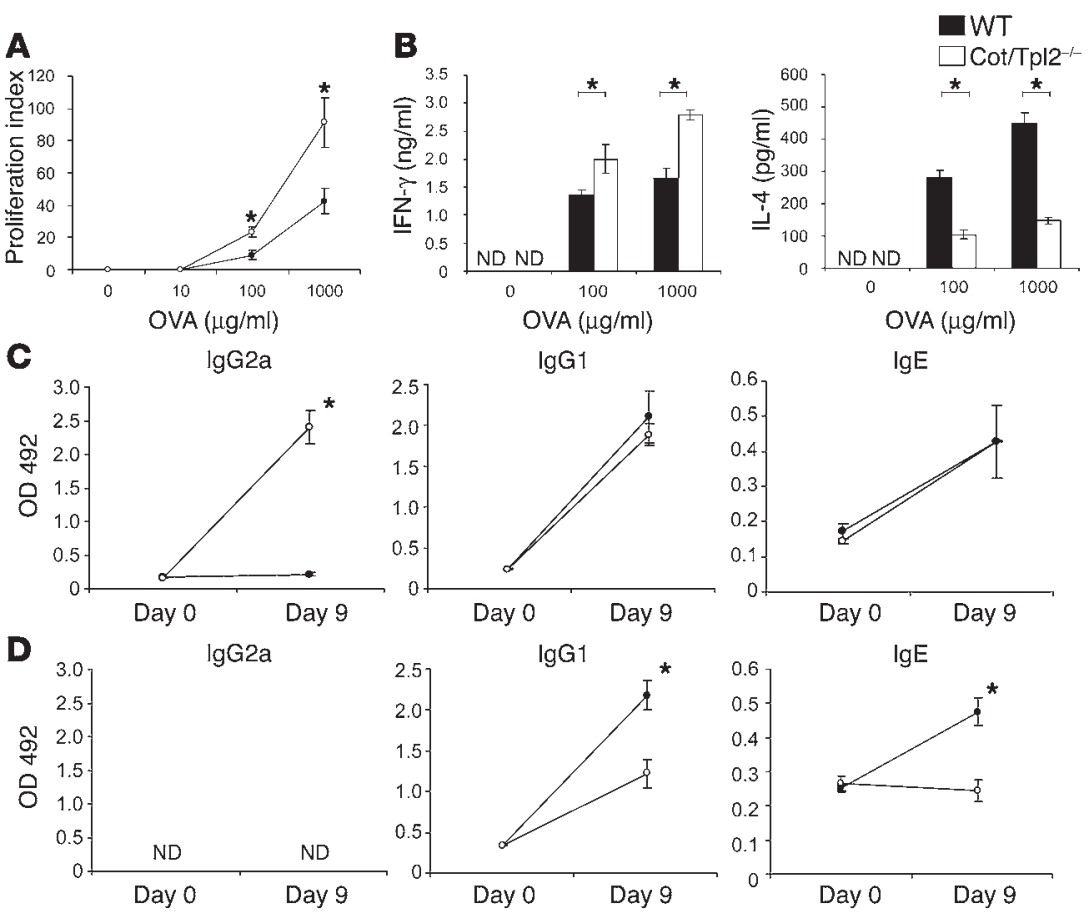

$\lg G 1$
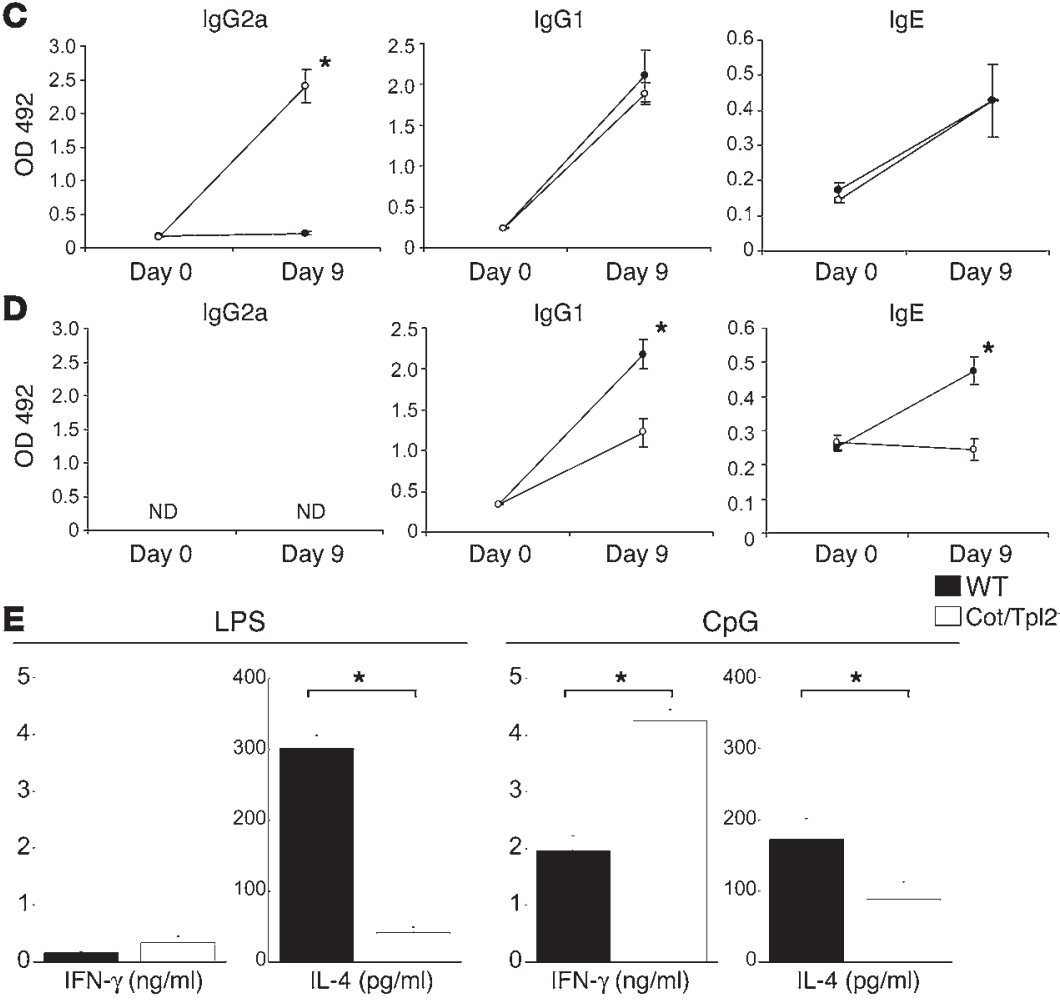

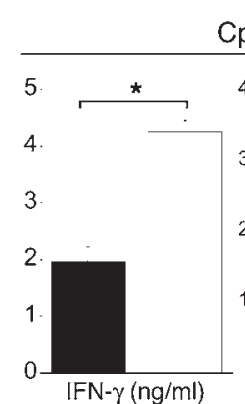

IFN- $\gamma(\mathrm{ng} / \mathrm{ml})$
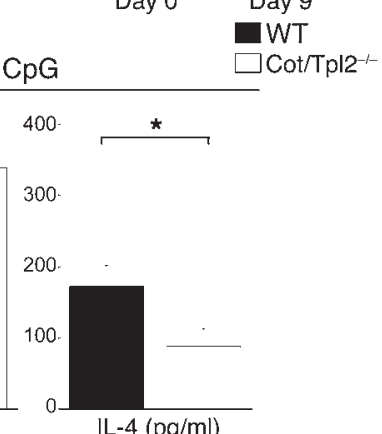

\section{Figure 6}

Antigen-specific Th1 cell responses were enhanced in Cot/Tpl2-/- mice. (A) Lymph node cells were collected from WT (filled circles, $n=4$ ) or Cot/Tpl2-/- mice (open circles, $n=4$ ) on day 9 after immunization with OVA in CFA. Proliferation of antigen-specific $T$ cells was analyzed by cell proliferation assay using cell culture supernatants in different concentrations of OVA for 72 hours.

(B) $\mathrm{CD}^{+} \mathrm{T}$ cells from lymph nodes of WT (black bars, $n=4$ ) or Cot/Tpl2 ${ }^{-1-}$ mice (white bars, $n=4$ ) immunized with OVA in CFA were cultured in different concentrations of OVA with APCs for 72 hours. Cytokines in supernatants of antigen-stimulated pooled cells were determined by specific ELISA. (C and D) Serum was collected from WT (filled circles, $n=5$ ) and Cot/Tpl2-/- mice (open circles, $n$ = 5) before (day 0) and after (day 9) immunization with OVA plus CFA (C) or OVA plus alum (D). OVAspecific lgG2a, OVA-specific lgG1, and OVA-specific IgE were analyzed. The $y$ axis indicates the OD value at $492 \mathrm{~nm}$. (E) CD4+ $\mathrm{T}$ cells from lymph nodes of WT (black bars, $n=3$ ) or Cot $/ \mathrm{Tpl} 2^{-/}$mice (white bars, $n=3$ ) immunized with OVA plus LPS or OVA plus CpG-DNA were cultured in the presence of OVA ( $1 \mathrm{mg} / \mathrm{ml})$ with APCs for 72 hours. Cytokines in supernatants of antigen-stimulated pooled cells were determined by specific ELISA. Data are expressed as mean of wells \pm SD and are representative of 3 independent experiments. ${ }^{*} P<0.05$.
$\mathrm{Tpl} 2$, which indicates that Cot/Tpl2 is widely involved in TLR signaling. Interestingly, however, unlike LPS or lipopeptide, CpG-DNA still activated ERKs in Cot/Tpl2-deficient macrophages, which suggests that there is an alternative Cot/Tpl2-independent ERK activation mechanism in TLR9 signaling. The uniqueness of the CPG-DNA/ TLR9 pathway has also been described in various other reports (23-25) and may partly be explained by the observation that TLR9 locates intracellularly while most other TLRs, including TLR4, locate on the cell surface (26). Thus, to gain access to the signaling compartment of the immune cells, a process referred to as endosomal maturation is required for CPG-DNA, but not for LPS (27).

The alternative pathway of ERK activation by CPG-DNA is sensitive to pretreatment with specific MEK1/2 inhibitors, which indicates that MEK1/2 is involved, probably directly upstream from ERKs (Figure 3C). ERK activation by CpG-DNA was also efficiently inhibited by staurosporine pretreatment. Since staurosporine was originally recognized as a PKC inhibitor, and 2 isoforms of PKC $(\varepsilon$ and $\delta$ ) were reported to be involved in LPS-induced signaling $(28,29)$, we then tested specific inhibitor peptides for PKC $\varepsilon$ and PKCס. However, neither inhibitor peptide inhibited CpG-DNAinduced ERK phosphorylation in Cot/Tpl2-/- macrophages (data not shown). Thus, the precise mechanisms of Cot/Tpl2-independent ERK activation remain ambiguous.
In the Cot/Tpl2-/- macrophages used in our study, decreased TNF- $\alpha$ secretion in response to LPS is consistently accompanied by lower levels of TNF- $\alpha$ mRNA. This result is apparently inconsistent with the previous report, in which LPS-induced TNF- $\alpha$ mRNA levels were not decreased in Cot/Tpl2-/- macrophages (17). The reason for this discrepancy is currently unknown. However, in support of our data, several groups reported that inhibition of the MEK/ERK pathway using a specific MEK inhibitor (U0126 or PD98059) resulted in decreased TNF- $\alpha$ mRNA induction by LPS $(30,31)$, which indicates that the decreased MEK/ERK activity leads to lower levels of TNF- $\alpha$ transcripts.

Another intriguing observation in our study is the enhanced IL-12 production in the Cot/Tpl2-deficient macrophages and DCs. Because of its critical role in the immune system (3), IL-12 production needs to be tightly regulated. Among factors proposed to inhibit IL-12 production, IL-10 is supposed to be a major negative regulator, because IL-10 gene-deficient mice showed spontaneous onsets of autoimmune disease-like phenotypes associated with increased IL-12 production (32). However, changes in IL-10 production are not likely to be involved in the enhanced IL-12 induction in CpG-DNA-stimulated Cot/Tpl2-/- macrophages or DCs, for the following reasons. First, IL-12 mRNA increased rather rapidly after CpG-DNA stimulation (Figure 4C), indicating that IL-12 

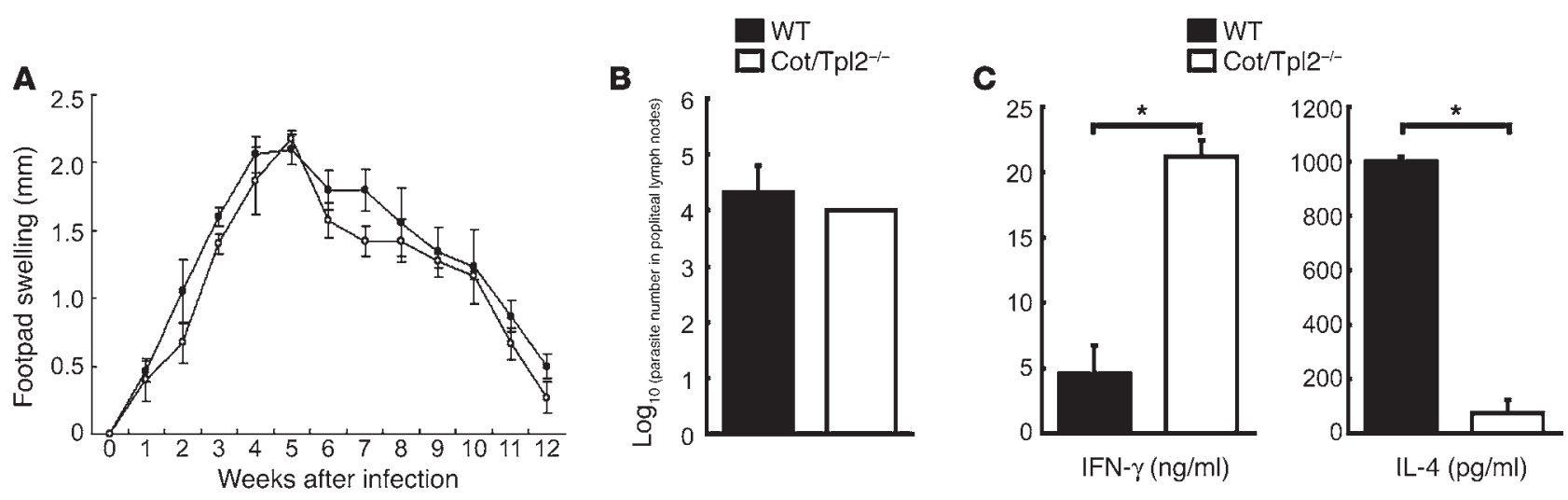

Figure 7

Increased Th1 response to L. major infection in Cot/Tpl2-/- mice. (A) The footpad swelling of age-matched WT (filled circles, $n=5$ ) and Cot/ $\mathrm{Tpl}^{-/-}$(open circles, $n=5$ ) mice infected with $L$. major was monitored on a weekly basis. (B) The number of $L$. major amastigotes in the popliteal lymph nodes of infected WT (black bars, $n=4$ ) and Cot/Tpl2-- mice (white bars, $n=4$ ) was examined 6 weeks after infection (see Methods). (C) $\mathrm{CD}^{+} \mathrm{T}$ cells were isolated from the lymph nodes of $L$. major-infected WT (black bars, $n=4$ ) or Cot/Tpl2 $2^{-/-}$mice (white bars, $\left.n=4\right)$ after 6 weeks of infection and cultured $\left(2 \times 10^{5}\right.$ per well in $200 \mu$ l of culture medium) with soluble $L$. major antigen $(30 \mu \mathrm{g} / \mathrm{ml})$ for 3 days. Cytokine production in the culture supernatants was examined by each cytokine-specific ELISA. Data are expressed as mean of wells \pm SD and are representative of 3 independent experiments. ${ }^{*} P<0.05$.

induction was likely to be directly activated by the treatment. Second, IL-10 levels induced by CpG-DNA are higher in Cot/Tpl2-/macrophages than in normal controls (Figure 4A). The mechanisms of increased IL-10 in Cot/T pl2/- macrophages are not clear. It is possible that increased IL-12 drives IL-10 production through IFN- $\gamma$ as a negative regulator of inflammation.

Previous reports indicated that MAPKs are critically involved in the regulation of IL-12 production in APCs. For example, activation of $\mathrm{p} 38$ MAPK has been related to enhanced IL-12 production, mainly at the transcriptional level (20). In contrast, Häcker et al. reported that inhibition of the MEK/ERK pathway by PD98059 or U0126 results in decreased TNF- $\alpha$ production and enhanced IL-12 production from APCs (33). In the current study, the mechanism of increased IL-12 production in Cot/Tpl2-/- APCs clearly did not involve ERK, since ERK phosphorylation remained intact in these cells; this indicates that Cot/Tpl2 deficiency increased IL-12 production by CPG-DNA without inhibiting ERK activation. Consistently, pretreatment with U0126 did not increase IL-12 production in WT nor Cot/Tpl2/- macrophages in response to CpG-DNA stimulation (Figure 4B). Together, our data indicated that CPG-DNA-induced ERK activity is not essential in regulating IL-12 production in primarily cultured macrophages.

On the other hand, correlation between mRNA and protein levels of IL-12 is consistent with a previous report indicating that IL-12 expression is primarily regulated at the transcriptional level in monocytic cells (20). Our EMSA results indicated that the induction of the negative regulators of IL-12 p40 transcription (c-Maf and GAP-12) by either LPS or CPG-DNA is significantly inhibited in Cot/T pl2 $/-$ macrophages (Figure 4D). In contrast, DNA binding of a positive regulator, NF- $\mathrm{KB}$, was similar between WT and $\mathrm{Cot} / \mathrm{T} \mathrm{pl} 2^{-/-}$macrophages. The 2 other reported positive regulators of the IL-12 p40 gene, Ets and C/EBP $\beta$, did not appear to be activated by LPS signals (22). GAP-12, whose molecular identity remains ambiguous, is a protein that binds to the suppressor site named GA-12 in the IL-12 p40 transcriptional regulatory region (21). Overexpression of c-Maf, another negative regulator, selec- tively inhibits transcriptional activation of both IL-12 p40 and IL-12 p35 genes (22). Thus the possibility may exist that GAP-12 and c-Maf are identical. However, this possibility was denied in a recent report, which showed that overexpression of c-Maf decreased protein binding of the GA-12 site in the IL-12 p40 gene (22). Thus, Cot/Tpl2 seems to be essential for the induction of 2 negative regulators of IL-12 p40 mRNA transcription.

It has been well established that DCs play essential roles in dictating this Th1/Th2 balance. PAMP-stimulated DCs express higher levels of MHC class II and costimulatory molecules and secrete significant amounts of IL-12, thus strongly inducing T cell differentiation toward a Th1 phenotype. Among the TLR ligands, CPG-DNA is one of the most potent inducers of IL-12. In this study, both LPS and CPG-DNA induced significantly higher levels of IL-12 secretion in Cot/Tpl2-/- DCs while increasing MHC class II and costimulatory molecule expression. It is of note that, unlike expression of costimulatory molecules such as CD86 and CD40, expression of MHC class II in Cot-Tpl2-/- DCs is moderately enhanced before PAMP stimulation (Figure 5A). The molecular mechanism of the increased MHC class II expression in Cot-Tpl2-DCs is currently unknown. Increased MHC class II expression may contribute to the Th1/Th2 balance of $\mathrm{CD} 4^{+} \mathrm{T}$ cells by affecting the intensity of antigen presentation $(34,35)$. DiMolfetto et al. (36) reported that, in mice expressing reduced levels of MHC class II but similar levels of costimulatory molecules on DCs, T cell response to antigen stimulation is skewed to Th1 type. Thus, increased MHC class II expression is not likely to be responsible for the skewed Th1 response in the Cot $/ \mathrm{Tpl}^{-/-}$condition. Taken together, these findings indicate that Cot/Tpl2 is not essential for the expression of costimulatory molecules but is specifically involved in IL-12 production in TLR-mediated signals.

Consistently, immunization of Cot/Tpl2-/- mice with OVA and CFA led to effective proliferation of antigen-specific $\mathrm{T}$ cells and increased IFN- $\gamma$ production. Since Ig class switching is regulated by cytokines from $\mathrm{T}$ cells $(37,38)$, we analyzed the profiles of antigen-specific Ig production in Cot/T $\mathrm{pl} 2^{-/-}$mice. Cot $/ \mathrm{T} \mathrm{pl} 2^{-/-}$mice 
exhibited increased levels of OVA-specific IgG2a production as compared with WT mice. On the other hand, immunization of Cot/Tpl2-/- mice with OVA plus alum, a strong inducer of Th2type immune responses, resulted in less IgG1 and IgE production than in the control mice. These results are consistent with the in vitro data of high IL-12 production and suggest that systemic responses to exogenous antigen are polarized toward Th1 type in $\mathrm{Cot} / \mathrm{Tpl} 2^{-/-}$mice. Notably, a quite recent report has revealed that Cot/Tpl2 is essential in CD40-mediated ERK activation in B cells (19). This ERK activation is decisive in IgE induction by CD40. Thus, defective ERK activation in B cells might also be responsible for the changes of antigen-specific Ig subtypes that we observed in OVA-immunized Cot/Tpl2-/- mice. It should also be noted that, besides IL-12, other cytokines produced by DCs, such as IL-18 and IL-23 $(39,40)$, contribute to the preferential Th1/Th2 $\mathrm{T}$ cell responses. Thus, further study is warranted to analyze these cytokines in Cot/Tpl2-/- mice.

In this study, we also tested the relevance of skewed Th1 response of Cot/Tpl2-/- mice using L. major, an infection model in which adequate Th1 development is required for disease control. Consistent with our data using OVA, we confirmed that Cot/ Tpl2-/- mice had enhanced Th1 responses against $L$. major challenge in $\mathrm{CD}^{+} \mathrm{T}$ cells (Figure $7 \mathrm{C}$ ). It has been reported that mice lacking MyD88 were more susceptible to L. major infection than control mice $(41,42)$. In these reports, a major parasite molecule, lipophosphoglycan, activated innate immune response via TLR2. It is also presumed that TLR9 is involved in the recognition of L. major, since protozoal DNA is largely nonmethylated and contains CpG immunostimulatory sequence (43). We also confirmed that HEK 293 cells transiently transfected with mouse TLR9 were responsive to the soluble L. major antigen (K. Sugimoto et al., unpublished observation), which indicates that a molecule in L. major, most likely L. major DNA, is recognized through TLR9. Inflammatory responses and parasite elimination, however, were not strongly altered in the $\mathrm{Cot} / \mathrm{Tpl} 2^{-/-}$mice. Since the strain we used, C57BL/6, is genetically resistant to L. major infection, a further increase in Th1 response might not be necessary for the protozoan elimination in this mouse strain. Another possibility is that decreased TNF- $\alpha$ secretion by macrophages impaired the clearance of L. major in Cot/Tpl2 $2^{-/}$mice (Figure 4A). Recent studies using gene-knockout technology have revealed that TNF- $\alpha$ is essentially involved in parasite elimination and resolution of inflammatory response against $L$. major infection $(44,45)$.

In summary, the activity of Cot/Tpl2 in macrophages and DCs appears to be decisive in determining IL-12 production and Th1/ Th2 balance both in vitro and in vivo. Since CPG-DNA-based adjuvant does not trigger the severe granulomatous reactions often seen with CFA, CpG-DNA's adjuvant property may be used beneficially in humans in the future. Simultaneous inhibitory operation of Cot/Tpl2 during CpG-DNA-guided vaccination may enhance Th1 response while further decreasing side effects caused by TNF- $\alpha$. Thus, Cot/Tpl2 may be considered as a potential target for immune therapy of diseases in which Th1/Th2 balance plays an essential role, such as allergy, infectious diseases, and cancer.

\section{Methods}

Generation of $\mathrm{Cot} / \mathrm{Tpl} 2^{-/-}$mice. A targeting construct was made to replace the $3^{\prime}$ half of coding exon 2 and the $5^{\prime}$ half of exon 3 , encoding the ATPbinding domain, with a neo-resistance gene cassette. CCE embryonic stem cells were transfected and selected as previously described (46).
Homologous recombinants were verified by Southern hybridization, and the resulting Cot $/ \mathrm{Tpl} 2^{+/-}$embryonic stem cells were microinjected into embryonic day 3.5 C57BL/6J blastocysts and transferred to $\mathrm{MCH}$ pseudopregnant foster mothers to generate chimeras that were mated with $\mathrm{BDF}_{1}$ mice for germ-line transmission. Mice with mutant alleles were backcrossed with C57BL/ 6 mice for more than 6 generations. Genotyping was performed by Southern hybridization and PCR using primers in the neo gene (5'-CCGCTTGGGTGGAGAGGCTAT-3' and 5'-TG-GTGGTCGAATGGGCAGGTA-3') and in the replaced Cot/Tpl2 gene (5'-AGAACACAAAGAGAATGAATG-3' and 5'-GCACCACAAAGAGTAGAAAAT-3'). After heterozygous mating, Cot $/ \mathrm{Tpl} 2^{-/-}$mice were born at the expected mendelian frequency, with life expectancy no different from that of WT littermates. RT-PCR (primers in the targeted region: $5^{\prime}$-TTCCCTGGCTGTCATCTGTCA-3' and 5'-GCACGCCATTCTTTTCTTTGT-3') and Western blot analysis ( $\mathrm{Ab}$ against the nontargeted $\mathrm{C}$-terminal region) confirmed that Cot/Tpl2 mRNA and protein were absent at the level of detection. All experiments were done in accordance with institutional guidelines of the Nagoya University Graduate School of Medicine.

Reagents and Ab's. LPS from Escherichia coli (serotype B6:055), synthetic lipopeptide (palmitoyl-Cys[(RS)-2,3-di(palmitoyloxy)-propyl]-Ala-Gly$\mathrm{OH}$ ), and synthetic CpG-DNA (5'-TCCATGACGTTCCTGATGCT-3') were obtained from Sigma-Aldrich, Bachem AG, and Rikaken Co., respectively. A polyclonal anti-Cot/Tpl2 $\mathrm{Ab}(\mathrm{M}-20)$, a polyclonal antiJNK1 Ab, a polyclonal anti-p38 Ab, a polyclonal anti-c-Maf Ab (M-153), and a monoclonal anti-histone $\mathrm{H} 1 \mathrm{Ab}(\mathrm{AE}-4)$ were obtained from Santa Cruz Biotechnology Inc. A polyclonal anti-ERK1/2 Ab, a phosphospecific anti-ERK1/2 polyclonal $\mathrm{Ab}$, and a phosphospecific anti-p38 MAPK polyclonal Ab were purchased from New England Biolabs Inc. Antimouse CD3 complex, anti-mouse CD45R/B220, and isotype control rat anti-mouse IgG2a Ab's were purchased from eBioscience. Monoclonal Ab against MHC class II was obtained from VMRD Inc. Rabbit complement was purchased from ICN Pharmaceuticals Inc. Phycoerythrin-conjugated anti-mouse CD80 (B7/BB1), anti-mouse CD86 (B7-2), and anti-I-A ${ }^{\mathrm{b}}$ and FITC-conjugated anti-CD11 $\mathrm{c}$ were purchased from BD Biosciences - Pharmingen. GST-MEK1 was purchased from Upstate Biotechnology Inc. U0126 and staurosporine were purchased from Calbiochem-Novabiochem Corp. and Sigma-Aldrich, respectively.

Cell preparation and culture. Thioglycollate-elicited peritoneal macrophages were isolated and cultured as previously described (17). Briefly, mice were injected intraperitoneally with $2.0 \mathrm{ml}$ thioglycollate broth (Sigma-Aldrich). Four days later, their peritoneal cavities were washed with $5 \mathrm{ml}$ of cold PBS. Cell pellets were washed and cultured at $1 \times 10^{6}$ cells $/ \mathrm{ml}$ for 2 hours. The dishes were washed twice with medium to remove nonadherent cells. At least $95 \%$ of the remaining adherent cells were macrophages according to Giemsa stains. To culture DCs, the bone marrow was isolated from the femurs and tibiae and depleted of erythrocytes. After washing, T cells, B cells, and MHC class II-positive cells were killed with a cocktail of Ab's (anti-mouse CD3 complex, anti-mouse CD45R/B220, and anti-MHC class II) and rabbit complement for 60 minutes at $37^{\circ} \mathrm{C}$. Cells $\left(1 \times 10^{6}\right)$ were cultured in RPMI 1640 supplemented with 5\% FBS, 10 mM HEPES, 10 $\mathrm{mM}$ sodium pyruvate, $50 \mu \mathrm{M} \beta$-mercaptoethanol, $100 \mathrm{U} / \mathrm{ml}$ penicillin, 100 $\mu \mathrm{g} / \mathrm{ml}$ streptomycin, and $10 \mathrm{ng} / \mathrm{ml}$ GM-CSF. Media were replaced every 2 days. The phenotype of immature DCs on day 5 was routinely greater than $60 \% \mathrm{CD} 11 \mathrm{c}^{+}$and greater than $95 \% \mathrm{CD} 11 \mathrm{~b}^{+}$without expression of CD8 $\alpha$. For ELISA, immature DCs were positively selected using magnetized Ab against CD11c (N418; Miltenyi Biotec Inc.). The resulting population was consistently greater than $85 \%$ CD $11 c^{+}$. The viability was greater than $90 \%$ according to trypan blue staining. On day 5 , immature DCs, defined as CD11 $\mathrm{c}^{+}$cells, were stimulated with LPS or CpG-DNA for 24 hours. CD4 ${ }^{+}$ $\mathrm{T}$ cells were purified from the draining popliteal lymph nodes by positive 
selection using magnetic beads conjugated with CD4 Ab (BD Biosciences - Pharmingen) according to the manufacturer's instructions. The purity of $\mathrm{CD} 4{ }^{+} \mathrm{T}$ cells was confirmed to be greater than $98 \%$ by flow cytometry. $\mathrm{CD} 4^{+} \mathrm{T}$ cells $\left(2 \times 10^{5}\right)$ were incubated in a 96-well plate with various concentrations of OVA or medium only, in the presence of $1 \times 10^{6}$ irradiated C57BL/6 splenocytes as APCs, for 72 hours.

Immunoblotting, immunoprecipitation, and in vitro kinase assay. Cell lysate preparation and immunoblotting were performed as previously described (47). Immunoprecipitation and in vitro kinase assays were carried out as previously described (47) except for the immunoprecipitation of Flagtagged Cot/Tpl2, in which Ab's were cross-linked to protein $\mathrm{G}$ beads.

Expression plasmids. The coding regions of mouse Cot/Tpl2 and TLR9 were amplified by RT-PCR from total RNA isolated from the mouse macrophage cell line RAW 264.7, or from spleen cells from C57BL/6 mice, and inserted, respectively, into the NotI-BamHI and NotI-EcoRI sites of the expression vector p3XFlag-CMV14 (Sigma-Aldrich), which encodes a C-terminal Flag epitope. The coding region of mouse MD2 was cloned into the KpnI-XhoI sites of a mammalian expression vector, pcDNA3.1(+) (Invitrogen Corp.). The coding region of mouse TLR4 was cloned into a mammalian expression vector, pcDNA4 Myc-His (Invitrogen Corp.). Mouse CD14 expression plasmid was constructed as previously described (48). The PCR primers used were: mouse Cot/Tpl2, 5'-TGCGGCCGCACCATGGAGTACATGAGCACT, 3'-CGGGATCCGCCGTATTCCAGGGTTGGTG; mouse TLR9, 5'-TTGCGGCCGCTCCCAACATGGTTCTCCGTC, 3'-CGGAATTCCCCTATTCTGCTGTAGGTCCCC; mouse MD2, 5'-GGGGTACCACCATGTTGCCATTTATTCTCT, 3'-CCGCTCGAGCTAATTGACATCACGGCGGTG; mouse TLR4, 5'-CGGGATCCACCATGATGCCTCCCTGGCTCC, 3'-TTTGCGGCCGCCGGTCCAAGTTGCCGTTTC. The structure of the constructs was confirmed by restriction enzyme mapping and DNA sequence analysis.

ELISA. The concentrations of TNF- $\alpha$, IL-10, IL-12 p40, IL-4, IFN- $\gamma$ (R\&D Systems Inc.), and IL-13 (BD Biosciences - Pharmingen) in culture supernatants were measured with commercial ELISA kits according to the manufacturer's instructions. All samples were assayed in triplicate, and the data were presented as the mean \pm SD.

Northern blot analysis and RPA. Northern blot analysis was performed as previously described (48). The TNF- $\alpha$ probe was prepared by RT-PCR using a pair of primers (sense, GGCAGGTCTACTTTGGAGTCATTGC; antisense, ACATTCGAGGCTCCAGTGAATTCGG) from total RNA of LPS-stimulated RAW 264.7 cells. RPA analysis was performed using the RiboQuant Multi-Probe RNase Protection Assay System and a DNA template set (mCK-2b) according to the manufacturer's instructions (BD Biosciences - Pharmingen).

EMSA. Nuclear extracts were prepared from thioglycollate-elicited peritoneal macrophages using NE-PER Nuclear and Cytoplasmic Extraction Reagents (Pierce Biotechnology Inc.) according to the manufacturer's instructions. EMSA was performed as previously described (48). The oligonucleotide sequences for EMSA were: NF-кB, 5'-AGTTGAGGGGACTTTCCCAGGC-3'; GA-12, 5'-CCTCGTTATTGATACACACACAGAGA-3'.

Immunization and challenge. Mice were immunized via injections into each hind footpad with $50 \mu \mathrm{g}$ of OVA (chicken egg albumin, fraction V; Sigma-Aldrich) in $25 \mu \mathrm{l}$ of saline emulsified 1:1 in CFA containing $1 \mathrm{mg} /$ $\mathrm{ml}$ of Mycobacterium tuberculosis (H37RA, heat-killed and dried; SigmaAldrich), $25 \mu$ l of saline emulsified in alum (Imject alum; Pierce Biotechnology Inc.), $25 \mu \mathrm{l}$ of incomplete Freund's adjuvant (IFA) containing 30 $\mu \mathrm{g}$ of LPS from E. coli (serotype B6:055), or $25 \mu \mathrm{l}$ of IFA containing 30 $\mu \mathrm{g}$ of CpG-DNA. The draining popliteal lymph nodes were isolated, and serum was collected on the indicated days for further analyses.

Cell proliferation assay. Cells from the draining lymph nodes were prepared after immunization of mice with OVA plus CFA. Lymph node cells $\left(3 \times 10^{5} / \mathrm{ml}\right)$ were cultured in the presence of various amounts of OVA for 72 hours. The CellTiter $96 \mathrm{AQueous}$ nonradioactive assay was used for the measurement of cell proliferation according to the manufacturer's instructions (Promega Corp.).

Determination of antigen-specific Ig isotypes. Serum was collected from the mice before (day 0 ) and after immunization (day 9 for immunization with OVA plus CFA or OVA plus alum), and OVA-specific IgE, IgG1, and IgG2a were analyzed. Briefly, $10 \mu \mathrm{g} / \mathrm{ml}$ of OVA was used to coat a microtiter plate overnight and then blocked with $1 \%$ BSA in borate-buffered saline $(0.05 \mathrm{M}$ borate, $0.15 \mathrm{M} \mathrm{NaCl}, \mathrm{pH} 8.6,100 \mu \mathrm{l} /$ well) at $37^{\circ} \mathrm{C}$ for 30 minutes. Diluted samples $(100 \mu \mathrm{l} /$ well) were incubated for 90 minutes at room temperature. The plates were washed with borate-buffered saline with $0.05 \%$ Tween-20 and incubated with peroxidase-conjugated anti-mouse IgE, IgG1, or IgG2a (Nordic Immunological Laboratories) for 90 minutes at room temperature. After further washing, plates were incubated for 20 minutes at room temperature with $100 \mu \mathrm{l} /$ well of $o$-phenylendiamine solution $(1 \mu \mathrm{g} / \mathrm{ml}$ with $3 \% \mathrm{H}_{2} \mathrm{O}_{2}$ ), and ODs were read at $492 \mathrm{~nm}$.

Flow cytometric analysis. Cells were stained with phycoerythrin- or FITCconjugated $\mathrm{Ab}$ 's at $4^{\circ} \mathrm{C}$ for 30 minutes. To block nonspecific FcR-mediated binding of the $\mathrm{Ab}$, mouse $\mathrm{CD} 16 / \mathrm{CD} 32 \mathrm{Ab}$ (eBioscience) was used. The cell surface expression of markers was assessed by a FACSCalibur (BD Biosciences).

L. major infection. L. major (MHOM/SU/73/5ASKH) was maintained by in vivo passage in $\mathrm{BALB} / \mathrm{c}$ mice. For experimental infection, the parasites were collected from the footpad and expanded in Schneider's medium (Invitrogen Corp.) supplemented with $20 \% \mathrm{FBS}$ at $25^{\circ} \mathrm{C}$. Promastigotes were harvested and washed with PBS. The mice were infected with $5 \times 10^{6}$ promastigotes in the right hind footpad. The footpad thickness was measured with a vernier caliper, and the swelling caused by infection was determined by the subtraction of the thickness of the uninfected left hind footpad from that of the infected right hind footpad. Six weeks after infection, mice were killed, and popliteal lymph nodes were removed for analyses of antigen-specific cytokine responses. Lymph nodes were homogenized with steel mesh, serially diluted fivefold with Schneider's Drosophila medium (Invitrogen Corp.) containing $20 \% \mathrm{FBS}$, and incubated at $25^{\circ} \mathrm{C}$. For 14 days after incubation, emerged promastigotes were monitored and the number of amastigotes in the lymph nodes was calculated by the maximal dilution in which promastigotes emerged. To prepare soluble leishmania antigens, $1 \times 10^{9}$ promastigotes were subjected to 3 cycles of freezing and thawing and homogenized.

Statistics. All values are expressed as mean $\pm \mathrm{SD}$, unless otherwise stated. Statistical analysis was performed using the Student's $t$ test. A $P$ value below 0.05 was considered statistically significant.

\section{Acknowledgments}

We thank K. Itano and A. Nishikawa for their technical assistance. This work was supported in part by grants from Ono Pharmaceutical Co., the Ministry of Education, Science, and Culture of the Japanese government, and the Yakult Bioscience Research Foundation.

Received for publication September 11, 2003, and accepted in revised form July 27, 2004.

Address correspondence to: T. Matsuguchi, Division of Biochemistry and Molecular Dentistry, Department of Developmental Medicine, Kagoshima University Graduate School of Medical and Dental Sciences, 8-35-1 Sakuragaoka, Kagoshima 890-8544, Japan. Phone: 81-99-275-6130; Fax: 81-99-275-6138; E-mail: tmatsugu@denta.hal.kagoshima-u.ac.jp. 
1. Aderem, A., and Underhill, D.M. 1999. Mechanisms of phagocytosis in macrophages. Annu. Rev. Immunol. 17:593-623.

2. Medzhitov, R. 2001. Toll-like receptors and innate immunity. Nat. Rev. Immunol. 1:135-145.

3. Trinchieri, G. 1995. Interleukin-12: a proinflammatory cytokine with immunoregulatory functions that bridge innate resistance and antigen-specific adaptive immunity. Annu. Rev. Immunol. 13:251-276.

4. Macatonia, S.E., et al. 1995. Dendritic cells produce IL-12 and direct the development of Th1 cells from naive CD4+ T cells. J. Immunol. 154:5071-5079.

5. Akira, S., Takeda, K., and Kaisho, T. 2001. Tolllike receptors: critical proteins linking innate and acquired immunity. Nat. Immunol. 2:675-680.

6. Higashi, T., et al. 1990. Hamster cell line suitable for transfection assay of transforming genes. Proc. Natl. Acad. Sci. U. S. A. 87:2409-2413.

7. Miyoshi, J., Higashi, T., Mukai, H., Ohuchi, T., and Kakunaga, T. 1991. Structure and transforming potential of the human cot oncogene encoding a putative protein kinase. Mol. Cell. Biol. 11:4088-4096.

8. Erny, K.M., Peli, J., Lambert, J.F., Muller, V., and Diggelmann, H. 1996. Involvement of the Tpl-2/ cot oncogene in MMTV tumorigenesis. Oncogene. 13:2015-2020.

9. Ceci, J.D., et al. 1997. Tpl-2 is an oncogenic kinase that is activated by carboxy-terminal truncation. Genes Dev. 11:688-700.

10. Salmeron, A., et al. 1996. Activation of MEK-1 and SEK-1 by Tpl-2 proto-oncoprotein, a novel MAP kinase kinase kinase. EMBO J. 15:817-826.

11. Chiariello, M., Marinissen, M.J., and Gutkind, J.S. 2000. Multiple mitogen-activated protein kinase signaling pathways connect the cot oncoprotein to the c-jun promoter and to cellular transformation. Mol. Cell. Biol. 20:1747-1758.

12. Tsatsanis, C., Patriotis, C., and Tsichlis, P.N. 1998 $\mathrm{T}$ pl-2 induces IL-2 expression in T-cell lines by triggering multiple signaling pathways that activate NFAT and NF-kappaB. Oncogene. 17:2609-2618.

13. Belich, M.P., Salmeron, A., Johnston, L.H., and Ley, S.C. 1999. TPL-2 kinase regulates the proteolysis of the NF-kappaB-inhibitory protein NF-kappaB1 p105. Nature. 397:363-368.

14. Lin, X., Cunningham, E.T., Jr., Mu, Y., Geleziunas, R., and Greene, W.C. 1999. The proto-oncogene Cot kinase participates in CD3/CD28 induction of NF-kappaB acting through the NF-kappaBinducing kinase and IkappaB kinases. Immunity. 10:271-280

15. Beinke, S., et al. 2003. NF-kappaB1 p105 negatively regulates TPL-2 MEK kinase activity. Mol. Cell. Biol. 23:4739-4752.

16. Waterfield, M.R., Zhang, M., Norman, L.P., and Sun, S.C. 2003. NF-kappaB1/p105 regulates lipopolysaccharide-stimulated MAP kinase signaling by governing the stability and function of the Tpl2 kinase. Mol. Cell. 11:685-694.

17. Dumitru, C.D., et al. 2000. TNF-alpha induction by LPS is regulated posttranscriptionally via a Tpl2/ ERK-dependent pathway. Cell. 103:1071-1083.

18. Eliopoulos, A.G., Dumitru, C.D., Wang, C.C., Cho, J., and Tsichlis, P.N. 2002. Induction of COX-2 by
LPS in macrophages is regulated by $\mathrm{Tpl} 2$-dependent CREB activation signals. EMBO J. 21:4831-4840.

19. Eliopoulos, A.G., Wang, C.C., Dumitru, C.D., and Tsichlis, P.N. 2003. Tpl2 transduces CD40 and TNF signals that activate ERK and regulates $\operatorname{IgE}$ induction by CD40. EMBO J. 22:3855-3864.

20. Lu, H.T., et al. 1999. Defective IL-12 production in mitogen-activated protein (MAP) kinase kinase 3 (Mkk3)-deficient mice. EMBO J. 18:1845-1857.

21. Becker, C., et al. 2001. Regulation of IL-12 p40 promoter activity in primary human monocytes: roles of NF-kappaB, CCAAT/enhancer-binding protein beta, and PU.1 and identification of a novel repressor element (GA-12) that responds to IL-4 and prostaglandin $\mathrm{E}(2)$. J. Immunol. 167:2608-2618.

22. Cao, S., et al. 2002. Differential regulation of IL-12 and IL-10 gene expression in macrophages by the basic leucine zipper transcription factor c-Maf fibrosarcoma. J. Immunol. 169:5715-5725.

23. Kawai, T., Adachi, O., Ogawa, T., Takeda, K., and Akira, S. 1999. Unresponsiveness of MyD88-deficient mice to endotoxin. Immunity. 11:115-122.

24. Doyle, S., et al. 2002. IRF3 mediates a TLR3/ TLR4-specific antiviral gene program. Immunity. 17:251-263.

25. Yamamoto, M., et al. 2002. Essential role for TIRAP in activation of the signalling cascade shared by TLR2 and TLR4. Nature. 420:324-329.

26. Ahmad-Nejad, P., et al. 2002. Bacterial CPG-DNA and lipopolysaccharides activate Toll-like receptors at distinct cellular compartments. Eur. J. Immunol. 32:1958-1968.

27. Häcker, H., et al. 1998. CpG-DNA-specific activation of antigen-presenting cells requires stress kinase activity and is preceded by non-specific endocytosis and endosomal maturation. EMBO J. 17:6230-6240

28. Monick, M.M., Carter, A.B., Flaherty, D.M., Peterson, M.W., and Hunninghake, G.W. 2000. Protein kinase $\mathrm{C}$ zeta plays a central role in activation of the p42/44 mitogen-activated protein kinase by endotoxin in alveolar macrophages. J. Immunol. 165:4632-4639.

29. Aksoy, E., Amraoui, Z., Goriely, S., Goldman, M. and Willems, F. 2002. Critical role of protein kinase C epsilon for lipopolysaccharide-induced IL-12 synthesis in monocyte-derived dendritic cells. Eur. J. Immunol. 32:3040-3049.

30. van der Bruggen, T., Nijenhuis, S., van Raaij, E. Verhoef, J., and van Asbeck, B.S. 1999. Lipopolysaccharide-induced tumor necrosis factor alpha production by human monocytes involves the raf-1/ MEK1-MEK2/ERK1-ERK2 pathway. Infect. Immun. 67:3824-3829.

31. Rutault, K., Hazzalin, C.A., and Mahadevan, L.C. 2001. Combinations of ERK and p38 MAPK inhibitors ablate tumor necrosis factor-alpha (TNFalpha) mRNA induction. Evidence for selective destabilization of TNF-alpha transcripts. J. Biol. Chem. 276:6666-6674.

32. Kuhn, R., Lohler, J., Rennick, D., Rajewsky, K., and Muller, W. 1993. Interleukin-10-deficient mice develop chronic enterocolitis. Cell. 75:263-274.

33. Häcker, H., et al. 1999. Cell type-specific activation of mitogen-activated protein kinases by CpG-DNA controls interleukin-12 release from antigen-pre- senting cells. EMBO J. 18:6973-6982.

34. Hosken, N.A., Shibuya, K., Heath, A.W., Murphy, K.M., and O'Garra, A. 1995. The effect of antigen dose on CD4+ T helper cell phenotype development in a $\mathrm{T}$ cell receptor-alpha beta-transgenic model. J. Exp. Med. 182:1579-1584

35. Constant, S., Pfeiffer, C., Woodard, A., Pasqualini, T., and Bottomly, K. 1995. Extent of T cell receptor ligation can determine the functional differentiation of naive CD4+ T cells. J. Exp. Med. 182:1591-1596.

36. DiMolfetto, L., Neal, H.A., Wu, A., Reilly, C., and Lo, D. 1998. The density of the class II MHC T cell receptor ligand influences IFN-gamma/IL-4 ratios in immune responses in vivo. Cell. Immunol. 183:70-79.

37. Stavnezer, J. 1996. Antibody class switching. Adv. Immunol. 61:79-146.

38. Manis, J.P., Tian, M., and Alt, F.W. 2002. Mechanism and control of class-switch recombination. Trends Immunol. 23:31-39.

39. Stoll, S., et al. 1998. Production of functional IL-18 by different subtypes of murine and human dendritic cells (DC): DC-derived IL-18 enhances IL-12-dependent Th1 development. Eur. J. Immunol. 28:3231-3239.

40. de Saint-Vis, B., et al. 1998. The cytokine profile expressed by human dendritic cells is dependent on cell subtype and mode of activation. J. Immunol. 160:1666-1676

41. de Veer, M.J., et al. 2003. MyD88 is essential for clearance of Leishmania major: possible role for lipophosphoglycan and Toll-like receptor 2 signaling. Eur. J. Immunol. 33:2822-2831.

42. Muraille, E., et al. 2003. Genetically resistant mice lacking MyD88-adapter protein display a high susceptibility to Leishmania major infection associated with a polarized Th2 response. J. Immunol. 170:4237-4241.

43. Brown, W.C., Estes, D.M., Chantler, S.E., Kegerreis, K.A., and Suarez, C.E. 1998. DNA and a CpG oligonucleotide derived from Babesia bovis are mitogenic for bovine B cells. Infect. Immun. 66:5423-5432.

44. Kanaly, S.T., Nashleanas, M., Hondowicz, B., and Scott, P. 1999. TNF receptor p55 is required for elimination of inflammatory cells following control of intracellular pathogens. J. Immunol. 163:3883-3889.

45. Wilhelm, P., et al. 2001. Rapidly fatal leishmaniasis in resistant C57BL/ 6 mice lacking TNF. J. Immunol. 166:4012-4019.

46. Koera, K., et al. 1997. K-ras is essential for the development of the mouse embryo. Oncogene. 15:1151-1159.

47. Matsuguchi, T., Musikacharoen, T, Johnson, T.R., Kraft, A.S., and Yoshikai, Y. 2001. A novel mitogen-activated protein kinase phosphatase is an important negative regulator of lipopolysaccharide-mediated c-Jun $\mathrm{N}$-terminal kinase activation in mouse macrophage cell lines. Mol. Cell. Biol. 21:6999-7009.

48. Matsuguchi, T., Takagi, K., Musikacharoen, T., and Yoshikai, Y. 2000. Gene expressions of lipopolysaccharide receptors, toll-like receptors 2 and 4, are differently regulated in mouse T lymphocytes. Blood. 95:1378-1385. 